\title{
Removal of Various Textile Dyes from Aqueous Solution Using Low Cost Biodegradable Adsorbent
}

\author{
Miraduzzaman Chowdhury, BSc \\ Mohammad Billal Hossain, Assistant Professor
}

Department of Textile Engineering, Primeasia University, Bangladesh

Doi: 10.19044/esj.2018.v14n36p298 URL:http://dx.doi.org/10.19044/esj.2018.v14n36p298

\begin{abstract}
In textile industry, dyes remove from solution using synthetic materials which is harmful for environment and expensive. In this research work acid treated saw dust(ATSD) used to remove of dyes from aqueous solution. It is environment friendly \& cheap. This research work has been carried out using Acid dye,1:2 metal complex dye, Acid-reactive dye, Reactive dye. The objective of work was how many dye separately removes from solution. Acid \& 1:2 metal complex dye removed from auxiliary free aqueous solution. In similar dye concentration(gm/l) less ATSD removes acid dye than 1:2 metal complex dye. By Beers-lambert law we explained the deviation of ATSD solution from standard solution of T\% \& Wavelength curve.
\end{abstract}

Keywords: Acid treated saw dust(ATSD), Environment friendly \& Cheap, Acid \&1:2 metal complex dye, auxiliary free aqueous solution, Beers-lambert law

\section{Introduction}

Bangladesh is $2^{\text {nd }}$ highest apparel exporter in world's textile market. For fulfil this demand there is establishment of a lot of textile factory in this subcontinent area. In case of increasing aesthetic property of cloth coloration various types of dyes are used in apparel.

The presence of very small amounts of dyes in water (less than $1 \mathrm{ppm}$ for some dyes) is highly visible and affects the aesthetic merit, water transparency and gas solubility in lakes, rivers and other water bodies (Mohammed et al., 2007).

There are more than 100,000 commercially available dyes with over 7 $\mathrm{x} 10^{5}$ of dyes produced annually worldwide processes (Ramaraju et al., 2014). However, these processes were very expensive and could not be effectively used to treat the wide range of dyes waste (Velmurugan et al., 2011). Many structural varieties of dyes exist, including acidic, basic, disperse, azo, diazo, 
anthraquinone based and metal complex dyes (Oguntimein et al., 2016). Dyes are chemicals, which on binding with a material will give color to them. Dyes are ionic, aromatic organic ompounds with structures including aryl rings, which have delocalized electron systems (Velmurugan et al., 2011). Textile industries produce vast amount of colored wastewater due to low level of dye fiber fixation (Oguntimein et al., 2016). The composition is very variable and can change quickly (Mohammed et al., 2007). Dyes, however, are more difficult to treat because of their synthetic origin and mainly complex aromatic molecular structures (Mohammed et al., 2007). Most dyes are made recalcitrant compounds through their interaction with sunlight in the effluent wastewater and can transform to carcinogenic compounds under anaerobic conditions (Chamargore et al., 2010). Effluent dyes released from industries constitute an important part of water pollution (Oguntimein et al., 2016). Effluent dye wastewater is a large volume production which can supplement limited fresh water resources if properly treated (Oguntimein et al., 2016). The conventional methods for the treatment of colored wastewater include chemical oxidation, coagulation and flocculation, ozonation, electrochemical techniques, fungal decolourisation, and adsorption. Adsorption is preferred to the other techniques in terms of initial cost, flexibility and simplicity of design, ease of operation, and insensitivity to toxic pollutants (Oyelude et al., 2012).

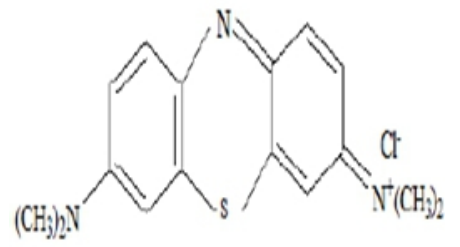

Fig 1. Methylene Blue

According to various dye classification, methylene blue is categorized as a highly toxic cationic dye (Oguntimein et al., 2016). cationic dye does not coagulate at all. Making their full removal by any technique is impossible (Joshi et al., 2004).

In the last decade, water resources have been decreased because of global warming and limited water treatment methods are available such as filtration, oxidation, sedimentation and adsorption (Chamargore et al., 2010). Adsorption method is an efficient and feasible wastewater treatment process which utilizes non-toxic, low cost and readily available adsorbents. These adsorbents are effective against a wide range of pollutants and a potential alternative for costly processes. Adsorbents range from commercial to low cost materials such as activated carbon, peat, organ clay, peanut husk, peanut hull, pine sawdust and oil palm ash. The environmental and cost advantages of non-conventional low cost adsorbents have prompted more research into 
this area. These advantages were summarized as follows:(i) Non-conventional adsorbent can compete favorably with conventional adsorbents in terms of efficiency depending on the characteristics and particle size of the adsorbents, and the nature of the adsorbate. (ii)Non-conventional adsorbents are cost effective; require simple alkali treatment, less maintenance and supervision (Oguntimein et al., 2016).

Table 1. Comparison for adsorption of some dyes on various adsorbent (Chamargore et al., 2010).

\begin{tabular}{|c|c|}
\hline Adsorbents & Dye(s) \\
\hline Duckweed & Methylene blue $^{9}$ \\
\hline Sewage Sludge & Basic red $^{10}$ \\
\hline Waste Newspaper & Basic Blue $^{11}$ \\
\hline Rice Husk & $\begin{array}{l}\text { Malachite Green }{ }^{12} \text { Acid } \\
\text { yellow }^{13}, \text { Acid blue }^{14}\end{array}$ \\
\hline Sugarcane bagasse & Acid orange $^{15}$ \\
\hline Coir Pith & Congo red ${ }^{16}$ \\
\hline Straw & Basic blue $^{17}$ \\
\hline Treated sawdust & Methylene blue $^{18}$ \\
\hline Neem leaf powder & Congo red ${ }^{19}$ \\
\hline Banana peel & Congo red $^{20}$ \\
\hline Bagasse fly ash & Congo red $^{21}$ \\
\hline Mahua oil cake & Congo red $^{22}$ \\
\hline
\end{tabular}

In our research work we were used acid treated saw dust(ATSD) as adsorbent which is biodegradable and economical. Hardwood sawdust is a very cheap and easily available material in developing countries. In Bangladesh it has not been investigated with much attention for its possibility as an adsorbent. Very limited work has been done on ATSD for removing textile dyes from aqueous solution. Previous work we followed "Low Cost Biodegradable Adsorbent Material for the Removal of Dissolved Dyes from Aqueous Solutions: An Economical Process" (Bozlur et al., 2010).

\section{Experimental}

\section{Chemicals and Materials Used}

Hardwood sawdust was collected from a local sawmill and dried in air at room temperature for some day and large particles were removed with a sieve size $190 \mu \mathrm{m}$. Small size of saw dust was selected in order to design consists properties of materials.

Erionyl Blue (Acid dye), Lanaset Blue (1:2 metal complex dye), Eriofast Blue (Acid-reactive dye), Novacron Blue (Reactive dye), Univadine (leveling agent), Albegal (crease preventive agent), Albaflow (penetration accelerate), Albatex (buffer of sodium acetate \& acetic acid) was supplied by "Swiss colours Bangladesh", Dhanmondi, Dhaka. 
Salt, Soda ash, wetting agent was supplied by Merck, India..

1. 100\% cotton knit fabric: Cotton is a Natural cellulosic fiber (E.P.G, 1975). It is used having greige 180 GSM of plain single jersey structure. We collected scoured \&bleached fabric from local market

2. 100\% polyamide knit fabric: Polyamide (Nylon 6:6) made by condensation of hexamethylene diamine and adipic acid (J.Gordon, 20112012).It is a spun from of polyhexamethylene adipamide (J.Gordon, 20112012). It is used having 220 GSM of plain single jersey structure. We collected scoured \&bleached fabric from local market.

3. Reactive dye: The molecular structures of reactive dyes resemble those of acid and simple direct cotton dyes, but with an added reactive group. Typical structures include the azo (a), anthraquinone (b), triphenodioxazine. The key structural features of a reactive dye are the chromophoric system, the sulphonate groups for water solubility, the reactive group, and the bridging group that attaches the reactive group either directly to the chromophore or to some other part of the dye molecule. The chromophoric system consist of azo, quinoid carbonyl, nitroso, nitro-group, carbonyl, vinyl group (-N=N-, C=O, $\mathrm{NO},-\mathrm{NO} 2,>\mathrm{C}=\mathrm{O},-\mathrm{C}=\mathrm{C}-$ ) etc unsaturated group. Each of these structural features can influence the dyeing and fastness properties.

4. Acid dye: Acid dyes are sodium salts of sulphonic acid or carboxylic acid $\&$ therefore anionic in aqueous solution Acid dyes usally are of many different chemical types. Sulphonated azo dyes constituent the major group and are mainly mono \& bi-azo compounds ranging in colour from yellow, through red to violet \& brown (Arthur, 2001).

5. 1:2 metal complex dye: It has two dye molecule for every metal atom(Chromium) \& apply slightly acid or neutral bath condition (E.P.G, 1975). The 1:2 metal complex dyes are applied from a slightly acid or neutral dye liquor. These dyes are soluble in an aqueous liquor because of the presence of anionic solublising group in dye molecule. The colored component of the dye is anionic and is attracted like acid dye to the positively charged amine groups of proteins and polyamide fibre(Arthur, 2001).Hue of 1:2 metal dye solution is duller which used for producing deep shade \& fastness property (E.P.G, 1975).

6. Acid reactive dye: It is popular for impart highest wet fastness properties $\&$ brilliant shades for polyamide fabric dyeing. It active on acid medium \& contains reactive group. 


\section{7. wetting agent}

8. salt

9. Sequestering agent

\section{Soda ash}

\section{Leveling agent}

12. Preventive agent

\section{Buffer solution}

\section{Penetration accelerating agent}

\section{Methods}

\section{Sawdust treatment process:}

20 gm sawdust mixed in $400 \mathrm{ml}$ water and $10 \mathrm{ml}$ of $98 \% \mathrm{HCL}$ was added to the mixer. Then the mixer was stirred 1 hour at $80^{\circ} \mathrm{C} \pm 2^{\circ} \mathrm{C}$ in a magnetic stirrer with hot plate (Stuart Scientific, SM-6, UK). The temperature rises up to that level within 30 minute. The sawdust was then filtered and dried in air at room temperature and termed as ATSD. During the activation it imparted an orange color to the water. Adsorbent treatment was carried out at Wet processing lab of Primeasia University.

\section{Dyeing of cotton fabric with reactive dye:}

Dyeing process occurred on Eco Dyer, Xiamen Rapid Co. LTD, Fujian China. Machine was running on 35 r.p.m.

Scoured \& bleached cotton fabric is subjected to reactive dyeing process.

\section{Recipe:}

Table 2: Recipe of cotton dyeing

\begin{tabular}{|l|l|}
\hline Reactive dye & $500 \mathrm{mg}$ \\
\hline Sequestering agent & $1 \mathrm{cc} / \mathrm{l}$ \\
\hline wetting agent & $1 \mathrm{cc} / 1$ \\
\hline salt & $50 \mathrm{gm} / 1$ \\
\hline Soda ash & $20 \mathrm{gm} / 1$ \\
\hline Sample weight & $10 \mathrm{gm}$ \\
\hline M:L & $1: 8$ \\
\hline
\end{tabular}

\section{Process:}

Dyeing process was done at $80^{\circ} \mathrm{C}$ for 40 minutes with the necessary chemicals mentioned in table-2. $\mathrm{pH}$ of solution was in alkali medium (9-10). Dyeing process is shown in figure- 2 


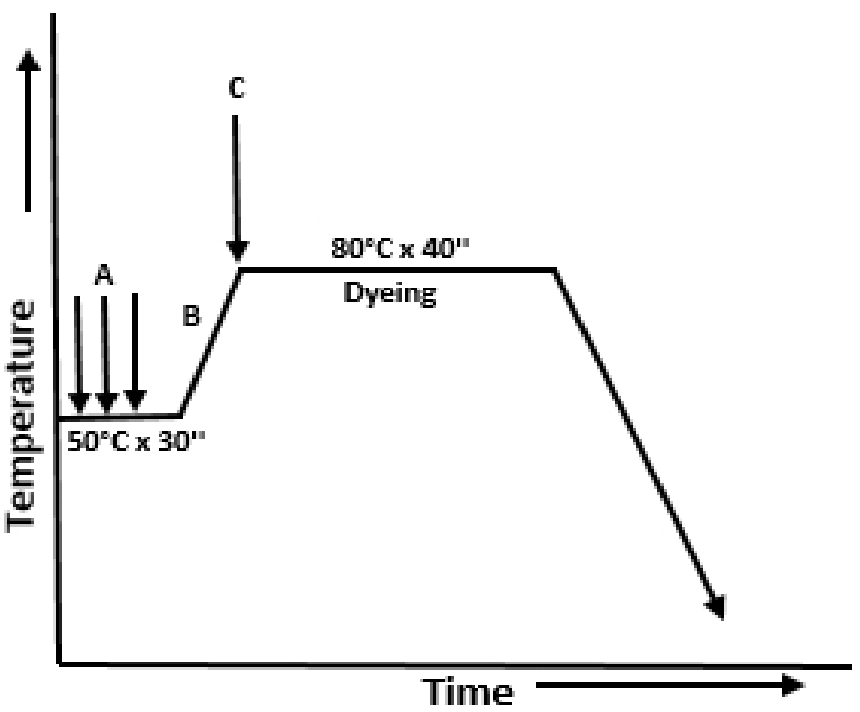

Figure 2: Dyeing process curve of cotton fabric

A $=$ All chemicals of dyeing was dosing at $50^{\circ} \mathrm{C}$

$\mathrm{B}=$ Temperature gradient was used $3^{\circ} \mathrm{C} / \mathrm{min}$

$\mathrm{C}=$ Soda ash dosing at $80^{\circ} \mathrm{C}$

\section{Collection of after reactive dyed solution:}

$1000 \mathrm{ml}$ after dyed solution was collected in a beaker.

Dyeing of Polyamide fabric with Acid /1:2 metal complex/Acid reactive dye:

Scoured \& bleached $100 \%$ polyamide fabric is subjected to Acid /1:2 metal complex/Acid reactive dyeing process.

\section{Recipe:}

Table 3: Recipe of polyamide fabric same for Acid /1:2 metal complex/Acid reactive dyes. $\mathrm{pH}$ of solution was in acidic medium (4.5-5).

\begin{tabular}{|l|l|}
\hline $\begin{array}{l}\text { Acid/1:2 metal complex/Acid reactive } \\
\text { dye }\end{array}$ & $500 \mathrm{mg}$ \\
\hline Levelling agent & $.5 \mathrm{gm} / 1$ \\
\hline Crease preventive agent. & $1 \mathrm{gm} / \mathrm{l}$ \\
\hline Buffer solution & $1 \mathrm{gm} / 1$ \\
\hline Penetration accelerate & $0.5 \mathrm{gm} / 1$ \\
\hline Sample weight & $10 \mathrm{gm}$ \\
\hline M:L & $1: 8$ \\
\hline
\end{tabular}




\section{Process:}

Dyeing process was done at $102^{\circ} \mathrm{C}$ for 40 minutes with the necessary chemicals mentioned in table-3. Dyeing process is shown in figure-3.

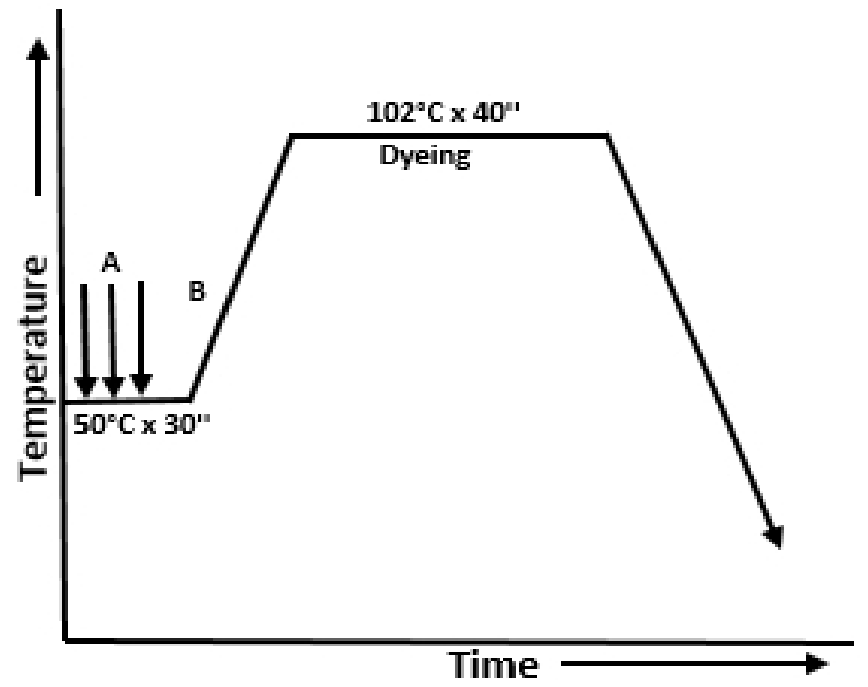

Figure 3: Dyeing process curve of cotton fabric

$\mathrm{A} \quad=$ All chemicals of dyeing was dosing at $50^{\circ} \mathrm{C}$

$\mathrm{B}=$ Temperature gradient was used $3^{\circ} \mathrm{C} / \mathrm{min}$

Collection of after Acid /1:2 metal complex/Acid reactive dyed solution: Separately, $1000 \mathrm{ml}$ after dyed solution was gathered in a beaker.

Preparation of auxiliary free reactive/acid/1:2 metal complex/acid reactive dye solution:

In $50^{\circ} \mathrm{C}$,separately auxiliary free $500 \mathrm{mg}$ reactive/acid/1:2 metal complex/acid reactive dye was mixed with $1000 \mathrm{ml}$ water $\&$ gathered in a beaker.

Treatment of after reactive/Acid/1:2 metal complex/Acid reactive dyeing solution with ATSD:

Separately,50gm ATSD mixed with after dyeing solution of reactive/Acid/1:2 metal complex/Acid reactive dye. A magnetic stirrer with hot plate was used to mix the solution properly.

Treatment of auxiliary free reactive/Acid/1:2 metal complex/Acid reactive dye solution with ATSD:

Separately, different amount of ATSD mixed with dye solution of reactive/Acid/1:2 metal complex/Acid reactive dye. A magnetic stirrer with hot plate was used to mix the solution properly. 


\section{Results:}

\section{Dye adsorption analysis}

ATSD has no effect on after reactive/Acid/1:2 metal complex/Acid reactive dyeing solution. Again it has no effect on directly prepared auxiliary free reactive/ Acid reactive dye solution. Only it adsorbs auxiliary free acid\&1:2 metal complex dye from solution. Acidity or Alkalinity of solution was measured by $\mathrm{pH}$ paper.

Different amount of ATSD used to identify amount of adsorption occurred on acid \& 1:2 metal complex dye solution.

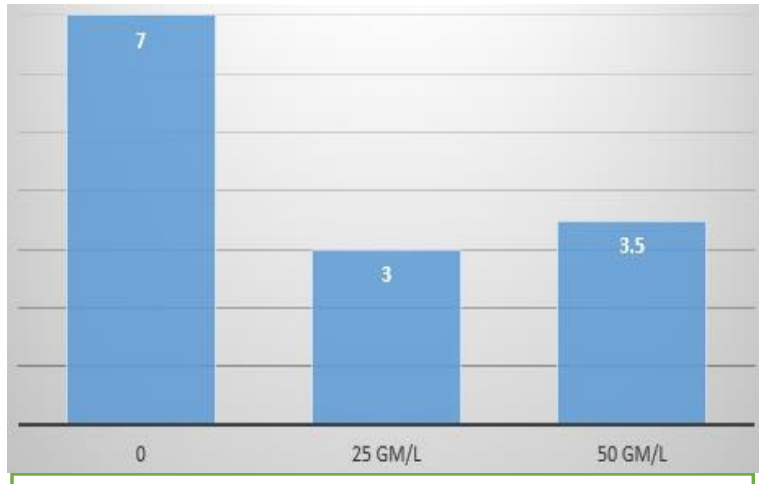

Fig 4.1 Connection of dosing amount(GM/L) \& $\mathrm{pH}$ for acid dye solution.

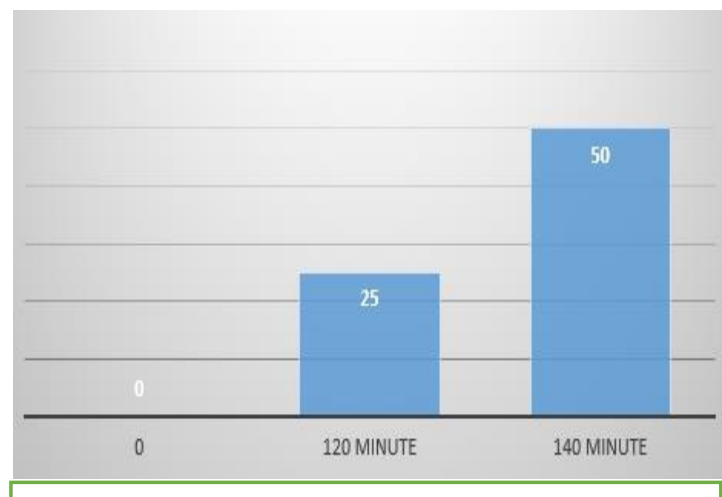

Fig 4.3 Connection of Stirring time(MINUTE) $\&$ Dosing amount $(\mathrm{GM} / \mathrm{L})$ for acid dye solution.

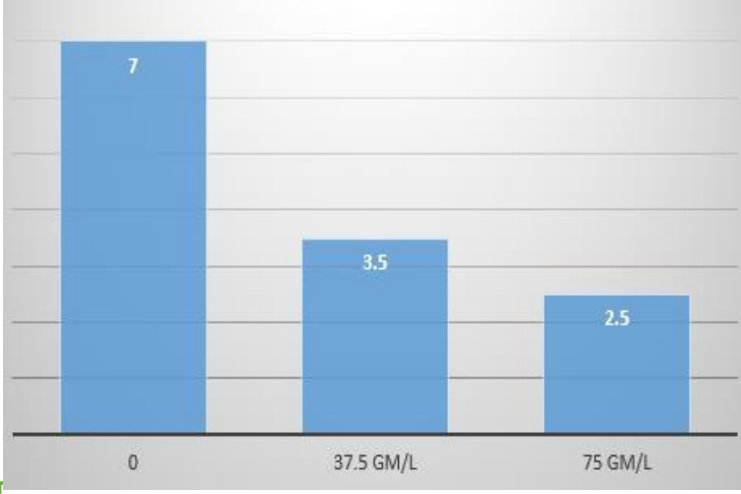

Fig 4.2 Connection of dosing amount(GM/L) \& $\mathrm{pH}$ for 1:2 metal complex dye solution.

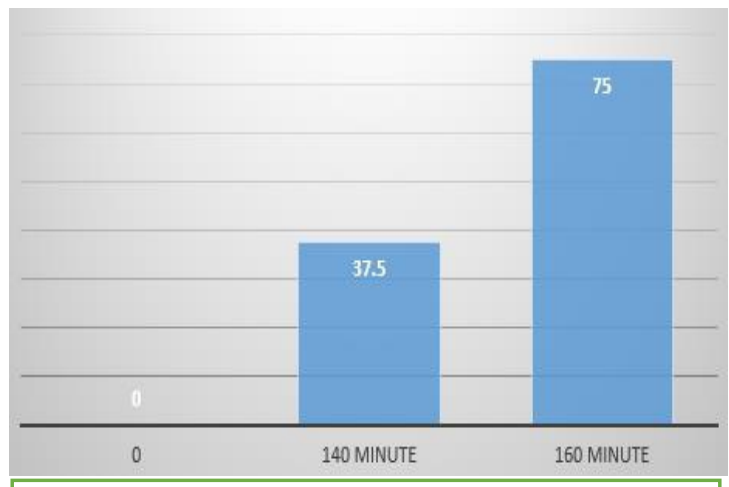

Fig 4.4 Connection of Stirring time(MINUTE) \& Dosing amount(GM/L) for 1:2 metal complex dye solution.

Connection of dosing amount \& $\mathrm{pH}$ for Acid dye,1:2 metal complex dye obtained in Fig 4.1,4.2. Connection of stirring time \& dosing amount of Acid dye,1:2 metal complex dye obtained in Fig 4.3,4.4. 
Standard acid \& 1:2 metal complex dye exhibits neutral medium in solution. Gradually increase of ATSD change solution towards acidic medium . Dosing amount $25 \mathrm{GM} / \mathrm{L}, 50 \mathrm{GM} / \mathrm{L}$ used in acid dye solution \& $37.5 \mathrm{GM} / \mathrm{L}, 75 \mathrm{GM} / \mathrm{L}$ used in 1:2 metal complex dye solution. When dosing amount increases, stirring time also rises to maximum 160 minutes.

\section{Analysis of solution with UV-Visible spectrophotometer Beers-lambert law}

This states that the absorbance of light energy of a specific wave length by an absorbing medium varies directly with the thickness of absorbing medium (also called optical path) and also varies directly with the concentration of the absorbing material (Roderick,1997).

\section{Spectrophotometric Analysis of solution}

The determination of specific transmittance $(\%)$ of light on liquid solution formed between ATSD \& Dye solution was carried by UV-Visible spectrophotometer, UV-1601, SHIMADZU corporation, Japan used from Pilot plant \& process development center of BCSIR, Dhanmondi, Dhaka, Bangladesh. Double cuvette used where one contain solution another was empty. Machine specified by remaining Scanning range (1100nm-190nm), Rec. Range (0\%-100\%), Scan Speed Medium, No. of scan-1, Display modesequential. According to beers-lambert law, transmittance (\%) of light generally a property of liquor solution which define dyes thickness of solution. Higher the T\% of solution in specific light area indicates less absorbency of light and also presentation of less dyes. We presented wavelength of visible light (400nm-700nm).

Maximum pick value of Red (740 to $635 \mathrm{~nm})$, Orange (635 to $590 \mathrm{~nm})$, Yellow (590 to $560 \mathrm{~nm}$ ), Green (560 to $520 \mathrm{~nm}$ ), Cyan (520 to $490 \mathrm{~nm})$, Blue (490 to $450 \mathrm{~nm}$ ), Violet (450 to $400 \mathrm{~nm}$ ) region light is exist on 6.1,6.2,6.3,6.4,6.5,6.6. 


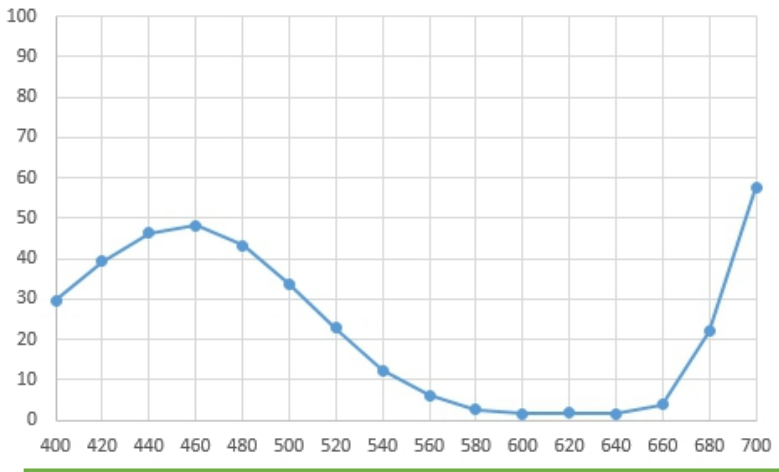

Fig 5.1 T\% \& Wavelength curve of Standard Acid dye solution.

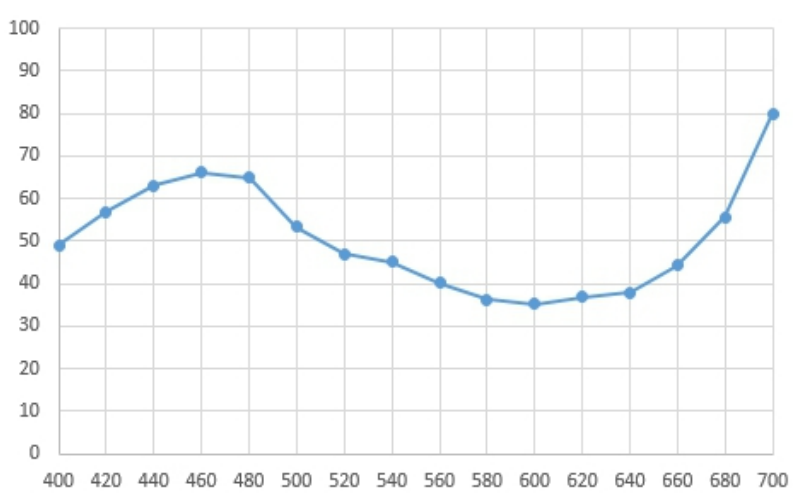

Fig 5.2 T\% \& Wavelength curve of 25gm/l ATSD treated dye solution.

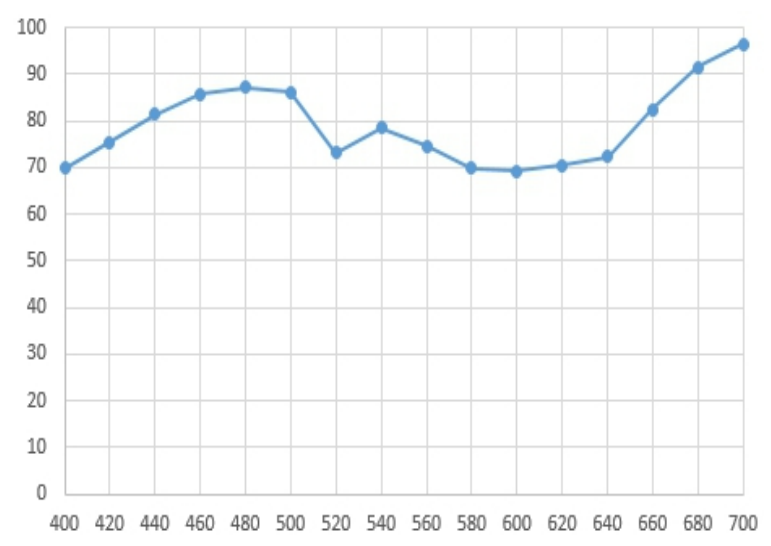

Fig 5.3 T\% \& Wavelength curve of 50gm/l ATSD treated dye solution.

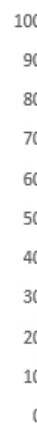

90
80
70
60
50
40
30
20
10
0

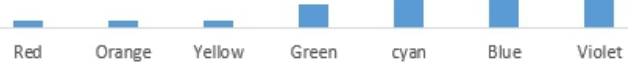

Fig 6.1 Connection of Specific light \& T\% for Standard Acid dye solution.

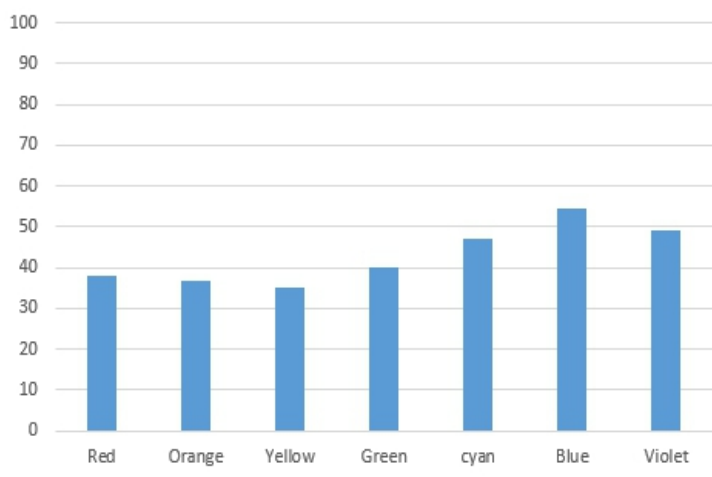

Fig 6.2 Connection of Specific light \& T\% for $25 \mathrm{gm} / 1$ ATSD treated dye solution.

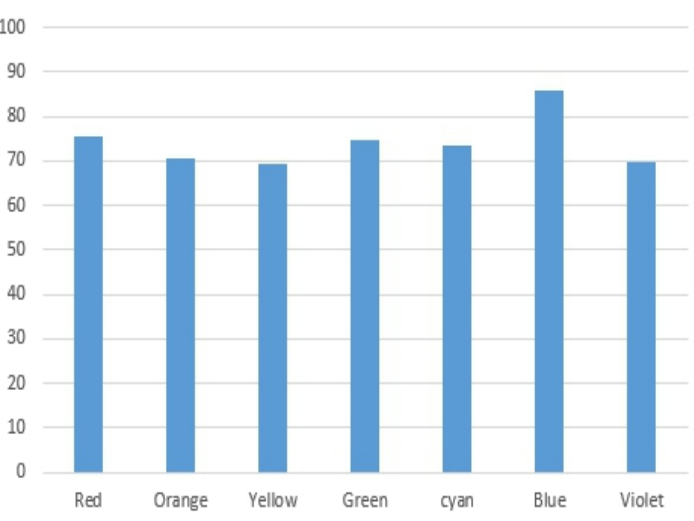

Fig 6.3 Connection of Specific light \& T\% for $50 \mathrm{gm} / \mathrm{l}$ ATSD treated dye solution. 
$\mathrm{T} \%$ \& wavelength curve of Acid dye solution exists on fig 5.1,5.2,5.3. After analyzing the curve fig 6.1,6.2,6.3 were found. In fig 6.2, Red, Orange, Yellow, Green, Cyan, Blue, Violet light compare to fig 6.1, transmittance (\%) of light higher than 22.8 times, 21.1 times, 23.1 times, 6.7 times, 2 times, 1.5 times, 1.6 times. In fig 6.3, Red, Orange, Yellow, Green, Cyan, Blue, Violet light compare to fig 6.1 transmittance (\%) of light higher than 45.5 times,70.5 times, 69.3 times, 74.6 times, 73.3 times, 85.7 times, 69.8 times.

Comparing Red, Yellow \& Blue light of Acid Dye Standard solution (Fig 6.1) \& 25gm/1 treated solution (Fig 6.2) where $25 \mathrm{gm} / 1$ treated solution transmittance (\%) is higher than $95.6 \%, 95.6 \%, 36.7 \%$.

Again Comparing Red, Yellow \& Blue light of $25 \mathrm{gm} / 1$ treated solution (Fig 6.2) \& 50gm/l treated solution (Fig 6.3) where 50gm/l treated solution transmittance $(\%)$ is higher than $49.8 \%, 49.6 \%, 36.4 \%$.

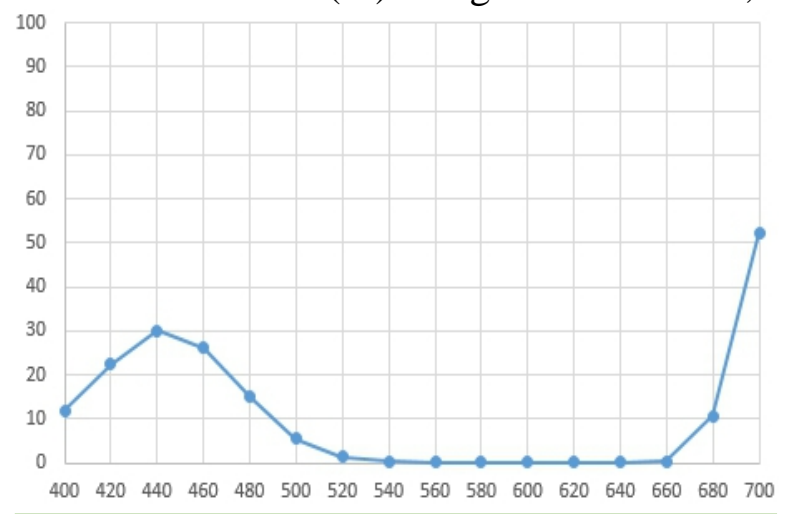

Fig 5.4 T\% \& Wavelength curve of Standard 1:2 metal complex dye solution.

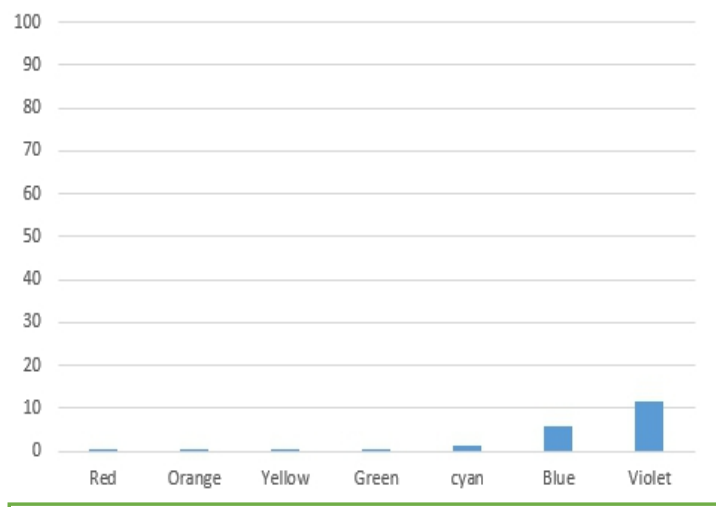

Fig 6.4 Connection of Specific light \& T\% for Standard 1:2 metal complex dye solution. 


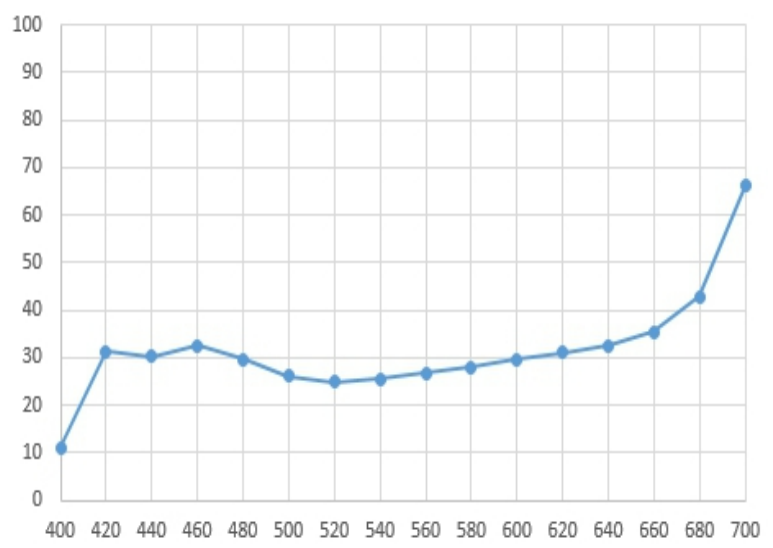

Fig $5.5 \mathrm{~T} \%$ \& Wavelength curve of $37.5 \mathrm{gm} / 1$ ATSD treated dye solution.

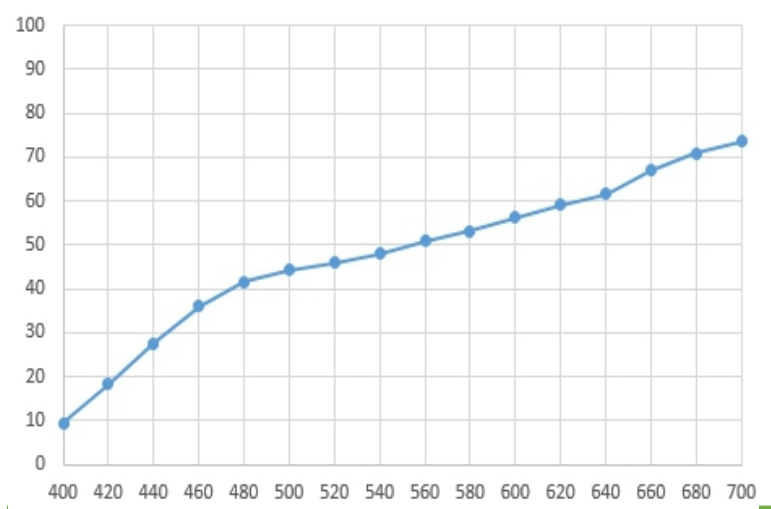

Fig 5.6 T\% \& Wavelength curve of $75 \mathrm{gm} / 1$ ATSD treated dye solution.

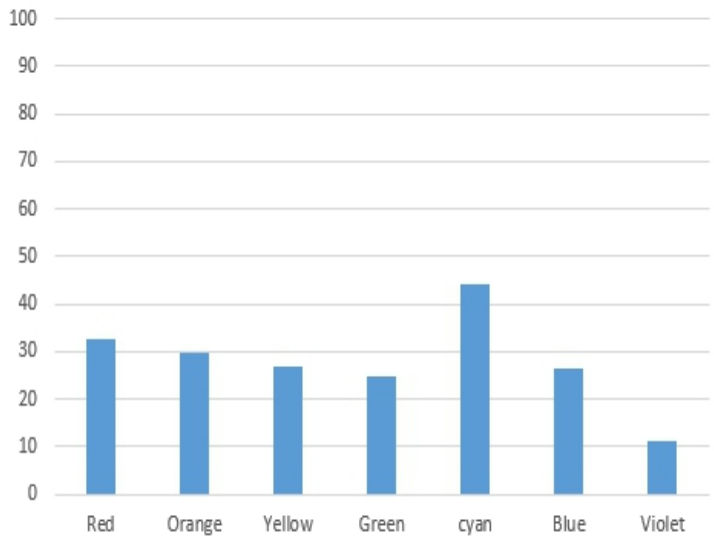

Fig 6.5 Connection of Specific light \& T\% for $37.5 \mathrm{gm} / 1$ ATSD treated dye solution.

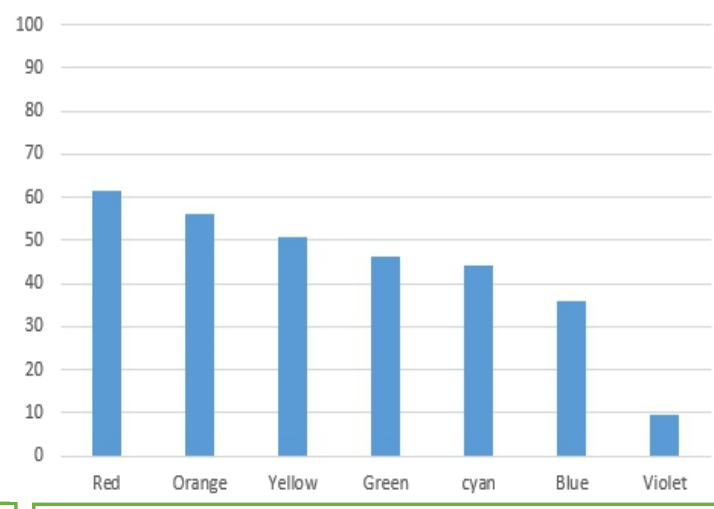

Fig 6.6 Connection of Specific light \& T\% for $75 \mathrm{gm} / \mathrm{l}$ ATSD treated dye solution.

T\% \& wavelength curve of 1:2 metal complex dye solution exists on fig 5.4,5.5,5.6. After analyzing the curve fig 6.4, 6.5, 6.6 were found. In fig 6.5 where Red, Orange, Yellow, Green, Cyan, Blue, Violet light compare to fig 6.4 transmittance (\%) of light higher than 136.8 times,348.6 times, 179.7 times, 151 times, 31.7 times, 4.4 times, 0.95 times. In fig 6.6 Red, Orange, Yellow, Green, Cyan, Blue, Violet light compare to fig 6.4 transmittance (\%) of light higher than 259.7 times, 661.2 times, 340.3 times, 279.1 times, 31.7 times, 6.1 times, 0.8 times.

Comparing Red, Yellow \& Blue light of 1:2 metal complex dye Standard solution (Fig 6.4) \& 37.5gm/l treated solution (Fig 6.5) where $37.5 \mathrm{gm} / 1$ treated solution transmittance $(\%)$ is higher than $99.2 \%, 99.4 \%, 77.6 \%$. 
Again Comparing Red, Yellow \& Blue light of $37.5 \mathrm{gm} / 1$ treated solution (Fig 6.5) \& 75gm/l treated solution (Fig 6.6) where $75 \mathrm{gm} / 1$ treated solution transmittance $(\%)$ is higher than $47.3 \%, 47.17 \%, 26.8 \%$.

Comparing Red, Yellow \& Blue light of 1:2 metal complex dye Standard solution (Fig 6.4) \& Acid dye Standard solution (Fig 6.1) where Acid Dye Standard solution transmittance $(\%)$ is higher than $85.7 \%, 90.2 \%, 82.9 \%$. So, Hue of 1:2 Metal complex standard dye solution is higher than 80times thicker of Acid dye standard solution.

$12.5 \mathrm{gm} / 1$ dosing amount extra in $37.5 \mathrm{gm} / 1$ treated $1: 2$ metal complex dye solution (Fig 6.5) compare to $25 \mathrm{gm} / 1$ treated acid dye solution (Fig 6.2). Red, Yellow \& Blue light of $25 \mathrm{gm} / 1$ treated acid solution transmittances $(\%)$ is higher than $14.5 \%, 24 \%, 51.8 \%$.

$25 \mathrm{gm} / 1$ dosing amount extra in $75 \mathrm{gm} / 1$ treated 1:2 metal complex dye solution (Fig 6.6) compare to $50 \mathrm{gm} / 1$ treated acid dye solution (6.3). Red, Yellow \& Blue light of 50gm/l (Fig 6.3) treated acid dye solution transmittances $(\%)$ is higher than $18.6 \%, 26.9 \%, 58.1 \%$.

\section{Discussions}

Result of ATSD after treat with auxiliary free Acid dye \& 1:2 metal complex dye found satisfactory. Hue of Standard 1:2 metal complex dye solution was thicker than standard acid dye solution. Because of use Blue color dye, every time complementary light yellow's transmittance (\%) was higher. Comparatively, after used higher dosing amount of ATSD, transmittance (\%) of major 3 light increased satisfactorily. Also seems using more adsorbent, $1: 2$ metal complex dye shows less transmittance (\%) of light compare to Acid dye.

\section{Conclusion}

The present study shows that ATSD could be an effective adsorbent for removing acid dyes \& 1:2 metal complex dyes from auxiliary free aqueous solution. According to Beers-lambert law in T\% \& wavelength curve less thickness of dyes achieved on $50 \mathrm{gm} / 1$ ATSD treated auxiliary free acid dye solution rather than $75 \mathrm{gm} / 1$ treated auxiliary free $1: 2$ metal complex dye solution. Auxiliary free acid dye solution transmittances $(\%)$ is higher than $18.6 \%, 26.9 \%, 58.1 \%$ compare to $1: 2$ metal complex dye. So, ATSD can use as a environment friendly \& cheap adsorbent to remove acid dyes \& 1:2 metal complex dyes from auxiliary free aqueous solution. Commercially it will be profitable if any effluent plant process is accepted.

\section{Acknowledgement}

During this work immense help was received from Mohammad Billal Hossain, Assistant Professor, Department of Textile Engineering, Primeasia University, Bangladesh. Special thanks to Mohammad Anowar Hossain, 
Mohammad Golam Nur, Assistant Professor, Department of Textile Engineering, Primeasia University for their inspiration.

\section{Referances}

1. Mohammed, W. T., Farhood, H. F., \& Al-Mas' udi, A. H. B. (2007). Removal of Dyes from Wastewater of Textile Industries Using Activated Carbon and Activated Alumina. Technical Paper, Chemical Engineering Department-College of Engineering-University of Baghdad-Iraq.

2. Ramaraju, B., Manoj Kumar Reddy, P., \& Subrahmanyam, C. (2014). Low cost adsorbents from agricultural waste for removal of dyes. Environmental Progress \& Sustainable Energy, 33(1), 38-46.

3. Chamargore, J. J., Bharad, J. V., Madje, B. R., \& Ubale, M. B. (2010). The removal of dye from aqueous solution by adsorption on low cost adsorbents. Journal of Chemistry, 7(3), 1003-1007.

4. Velmurugan, P., Kumar, R. V., \& Dhinakaran, G. (2011). Dye removal from aqueous solution using low cost adsorbent. International journal of environmental sciences, 1(7), 1492.

5. Oguntimein GB. Textile Dye Removal using Dried Sun Flower Seed Hull a New Low Cost Bio sorbent: Equilibrium, Kinetics and Thermodynamic Studies. Adv Res Text Eng. 2016; 1(1): 1008.

6. Oyelude, E. O., \& Appiah-Takyi, F. (2012). Removal of methylene blue from aqueous solution using alkali-modified malted sorghum mash. Turkish Journal of Engineering and Environmental Sciences, 36(2), 161-169.

7. Joshi, M., Bansal, R., \& Purwar, R. (2004). Colour removal from textile effluents. Indian Journal of Fiber \& Textile Research,Vol 29 June 2004, pp. 239-259.

8. Bozlur, R. M., Shibata, S., Diba, C. F., \& Uono, M. (2010). Low Cost Biodegradable Adsorbent Material for the Removal of Dissolved Dyes from Aqueous Solutions: An Economical Process. International Journal of Engineering and Technology, 2(5), 468.

9. E.P.G Ghol, L.D. Vilensky, Textile Science, Melbourne, Australia, 1983.

10. Arthur D Broadbent, Basic principles of Textile Coloration, Society of dyers and colourists, England,2001.

11. E.R. TROTMAN, DYEING AND CHEMICAL TECHNOLOGY OF TEXTILE FIBRES, $5^{\text {th }}$ edition, London and high Wycombe, 1975.

12. J.Gordon Cook, Handbook Of Textile Fibers, Cambridge England,2011-2012.

13. Roderick McDonald, Colour Physics for Industry, Society of dyers and colourists, England,1997. 